\title{
Aprovechamiento de los lodos urbanos en la agricultura
}

\author{
Gonzalo Miragaya García
}

Alicia Benarroch Benarroch

\section{Introducción}

Los productos finales obtenidos en una depuradora de aguas residuales urbanas, el agua tratada, el fango o lodo y el biogás, presentan amplias posibilidades de aprovechamiento que están siendo continuamente investigadas bajo los tres aspectos fundamentales: económico, técnico y sanitario.

Los lodos de las depuradoras urbanas ofrecen, por su composición físicoquímica, amplias posibilidades de empleo en agricultura. Estos lodos, con un notable contenido en materia orgánica, sustituyen parcialmente al abono orgánico tradicional, el estiercol animal, paliando la escasez del mismo, y, además poseen una considerable capacidad fertilizante, debido a los macronutrientes minerales presentes, principalmente el Nitrógeno y el Fósforo.

El creciente aumento de precio de los fertilizantes, tanto orgánicos como minerales, abre nuevas perpectivas en el empleo de los lodos urbanos en la agricultura.

La carga económica que supone para el mantenimiento de una Estación Depuradora de Aguas Residuales la evacuación y transporte a vertederos de estos lodos, previo acondicionamiento de los mismos, es una nueva razón para su empleo en la agricultura pues permite algún tipo de autofinanciación.

Por último, hay que tener en cuenta el volumen de fangos para ser añadidos a los residuos sólidos urbanos a eliminar, que en una ciudad como Melilla, supone un incremento del $27 \%$ sobre las basuras totales recogidas y que se hará patente, en un futuro, en la carga de trabajo de la incineradora.

TRATAGUA, S.A., como entidad explotadora de este tipo de depuradoras de aguas residuales, y con el fin de mejorar la prestación de sus servicios, ha iniciado una primera etapa de experimentación encaminada a determinar la calidad de los lodos producidos en la depuradora de Melilla y su posible utilización como fertilizantes.

\section{Parte experimental}

\section{II.1.- Huerta experimental}

La mencionada primera etapa de experimentación iniciada en Febrero de 
- Estimula la actividad biológica.

Para determinar la fracción orgánica de los lodos se utiliza el tanto por ciento de materia orgánica sobre materia seca y el dato experimental promedio obtenido en el lodo utilizado ha sido:

Materia Orgánica (M.O.): 50,4\% sobre materia seca.

b) El Nitrógeno es el elemento que más incide sobre la producción agrícola disminuyendo su rendimiento tanto por exceso como por defecto.

El nitrógeno de los lodos es principalmente órganico siendo muy poco el nitrógeno mineral (amoniaco, nitritos, nitratos...). Si tenemos en cuenta que el necesario para las plantas es Nitrógeno mineral, hay que dejar un tiempo para que el Nitrógeno orgánico capaz pueda mineralizarse. En consecuencia, el efecto fertilizante del Nitrógeno se consigue a largo plazo.

El contenido en $\mathrm{N}$ total del lodo utilizado ha sido del $3 \%$ en $\mathrm{N}$ hidrolizable del $2.3 \%$.

c) El Fósforo, en forma de fosfatos, es ampliamente utilizado como fertilizante agricola. El lodo urbano contiene fósforo en dos formas: en forma de fosfatos, directamente asimilable por las plantas y en forma de fósforo orgáni$\infty$, cuya asimilación dependerá, como en el caso del Nitrógeno, de su grado de mineralización.

El contenido en Fósforo de un abono se expresa en forma de $\mathrm{P}_{2} \mathrm{O}_{5}$ total. El porcentaje de $\mathrm{P}_{2} \mathrm{O}_{5}$ citado por la bibliografía para un fango urbano es del $3,2 \%$. Nosotros no pudimos por carencia de medios realizar el análisis de fósforo de nuestro lodo.

d) El Potasio, es también un elemento fertilizante ampliamente utilizado. Sin embargo, los lodos urbanos carecen de concentraciones altas de potasio puesto que las sales de potasio son muy solubles en el agua y, por tanto, suelen marchar con el agua tratada. El contenido medio de Potasio citado por la bibliografía es de $0,3 \%$ de $\mathrm{K}_{2} \mathrm{O}$.

En consecuencia, los contenidos promedio de los elementos macrofertilizantes registrados según el análisis de nuestros lodos expresados en materia seca, son:

$\begin{array}{ll}\text { M.O. oxidable } & 50,4 \% \text { en M.O. } \\ \text { Nitrógeno } & 3 \% \text { en N. } \\ \text { Fósforo } & 3,2 \% \text { en } \mathrm{P}_{2} \mathrm{O}_{5} \\ \text { Potasio } & 0,3 \% \text { en } \mathrm{K}_{2} \mathrm{O}\end{array}$

La Ley de Abonos (10 Junio 1976) calificaciria estos lodos como "Abono Orgánico" al cumplir las especificaciones de composición de M.O. mínima $35 \%$ y sumas totales de $\mathrm{N}, \mathrm{P}_{2} \mathrm{O}_{5}$ y $\mathrm{K}_{2} \mathrm{O}$ superior al $6 \%$ con un mínimo del $2 \%$ de $\mathrm{N}$ orgánico del cual un $80 \%$ sería insoluble en agua.

\section{II.3.- Composición del suelo}

El suelo de la huerta experimental había sido rellenado, al igual que toda la EDAR, con la tierra vegetal que hubo de ser retirada para la construcción de una planta de hormigón de la Huerta de los hermanos Serón, situada en la zo- 
na agrícola de la Carretera de Farhana. De ahí que fuera una tierra rica en materia orgánica. Un análisis en nuestro laboratorio revelaba una dosis del $10 \%$ de M.O. sobre la materia seca.

\section{II.4.- Resultados}

La situación de las plantas que sobrevivieron el día 1-7-85 puede observarse en el gráfico adjunto:

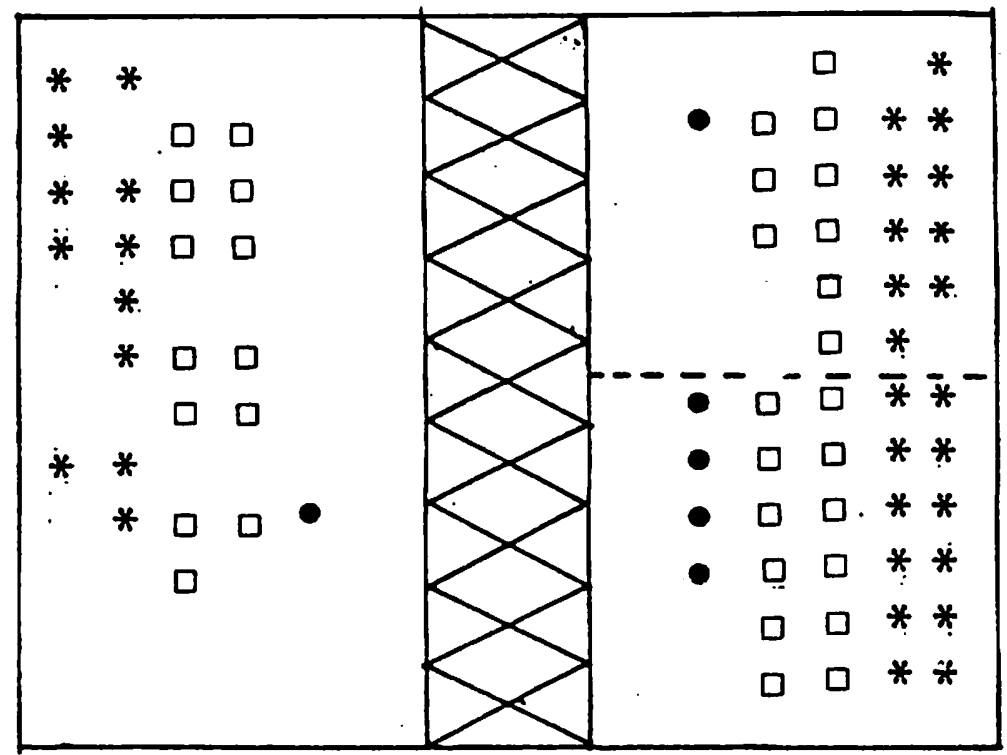

Donde puede hacerse la observación de que no sólo es mayor el número de plantas de la zona derecha sino que dentro de ésta sobrevivieron más plantas en la zona $D$, dosificada con mayor cantidad de fango que en la zona $C$.

Los frutos fueron recogidos cuando ya tenían color pero cuando aún no estaban maduros para los tomates; no así para los melones que conviene dejarlos madurar antes de recogerlos.

Las cantidades en Kgs. de frutos recogidos de las zonas A, C y D, se resumen en la tabla adjunta:

\begin{tabular}{lcc|c|c|} 
& ZONA “A” & ZONA “C” & ZONA “D” & ZONA “C” + "D" \\
\hline Tomates & 104,04 & 90,03 & 110,56 & 200,59 \\
\hline Pimientos & 50,17 & 32,50 & 50,69 & 83,19 \\
\hline Melones & 8,9 & 10,34 & 35,42 & 45,76 \\
\hline
\end{tabular}


Es necesario señalar la falta de cualificación de los que realizaron las siembras, el cuidado y recolección de los frutos pues éstos fueron operadores de la planta depuradora, con lo cual se cometieron fallos que, posteriormente analizados, servirán para evitarlos en una próxima siembra.

Por último, un análisis de resultados que son sin duda favorables a las zonas $\mathrm{C}$ y D, nos afirman una vez más la gran utilidad de los fangos como abono en la agricultura. No dudamos que en un futuro, dichas diferencias se vayan incrementando.

\section{Riesgos sanitarios}

El manejo y uso de lodos implica riesgos sanitarios tanto por su contacto más o menos directo con personas y cultivos como por la posible incorporación de metales pesado en los suelos o en la cadena trófica.

a) Riesgos microbiológicos. - Los residuos humanos son la principal fuente de contaminación microbiólogica de las aguas residuales urbanas y de los lodos. Los microorganismos se acumulan en su mayor parte en los lodos durante la decantación secundaria. Así la salmonella se acumula en los lodos entre el 40 y el $60 \%$; la E. coli se decanta con el lodo en su mayoría; toda la población de Microbacterium tuberculosis reviste el proceso de digestión y se acumula en los lodos; esto mismo parece ocurrir con las pseudomonas, vibrios, shigella aunque no se conoce tan bien se evolución en el proceso. Se han identificado unos 100 serotipos de virus en lodos de depuradora; la mayoría son patógenos del hombre y de los animales. Esto mismo ocurre con los protozoos y parásitos intestinales.

Aunque si bien existen medios de desinfección eficaces, tales como procesos térmicos, cambios de $\mathrm{pH}$, irradiaciones de $60_{\mathrm{co}_{0}}$ y $137_{\mathrm{cs}}$, un gran $\mathrm{n} . .^{\circ}$ de controles manifiestan que una exposición al sol de 24 horas, eliminan el $95 \%$ de microorganismos patógenos.

b) Riesgos por toxicidad. - Además de la materia orgánica, el nitrógeno y fósforo, los lodos urbanos contienen bastantes elementos en concentraciones de trazas u oligoelementos indispensables para el crecimiento de los vegetales y que algunos suelos carecen ( $\mathrm{Fe}, \mathrm{Mn}, \mathrm{Zn}, \mathrm{Mo}, \mathrm{B})$. Estos micronutrientes en exceso, pueden convertirse en tóxicos y su toxicidad puede acentuarse si los lodos contienen además metales pesados $(\mathrm{Cd}, \mathrm{Ni}, \mathrm{Pb})$ como consecuencia de vertidos industriales a las redes de alcantarillado.

Los riesgos de toxicidad química pueden ser inmediatos si la presencia de estos elementos en los suelos es elevada pues inhiben el crecimiento de las plantas o emigran a través de la cadena alimentaria afectando al hombre. Estos riesgos pueden presentarse a largo plazo. La adición repetitiva de estos micronutrientes, aunque sea en pequeña cantidad, puede producir acúmulo en el suelo y, con el tiempo desarrollar efectos tóxicos.

Los valores límites expresados por la norma A.F.N.O.R. V-44041 para que los lodos urbanos no signifiquen riesgo tóxico, se reflejan en la relación siguiente: 
Zinc .........3.000 mg/kg. materia seca.

Manganeso....1.500 mg/kg. materia seca.

Cobre ...... $500 \mathrm{mg} / \mathrm{kg}$. materia seca.

Plomo...... $300 \mathrm{mg} / \mathrm{kg}$. materia seca.

Cromo....... $200 \mathrm{mg} / \mathrm{kg}$. materia seca.

Níquel...... $100 \mathrm{mg} / \mathrm{kg}$. materia seca.

Cadmio...... $20 \mathrm{mg} / \mathrm{kg}$. materia seca.

Mercurio..... $15 \mathrm{mg} / \mathrm{kg}$. materia seca.

En el caso de nuestros lodos, la ausencia en nuestra ciudad de centros industriales, los excluye de estos riesgos. Un cambio en un momento determinado de las actividades industriales de nuestra ciudad implicaría una revisión de la aplicabilidad de los lodos en la agricultura.

\section{Valoración Económica}

El contenido promedio de los elementos macrofertilizantes de nuestros lodos expresado en materia seca es:

Materia Orgánica.........50,4\% en M.O.

Nitrógeno.............. $3 \%$ en $\mathrm{N}$.

Fósforo.............. $3,2 \%$ en $\mathrm{P}_{,} \mathrm{O}_{4}$.

Potasio............... 0,3\% en $\mathrm{K}_{2} \mathrm{O}$

Los precios actuales (Cros, Agosto 1985) de los ahonos quimicos en los que el Nitrógeno, el Fósforo y el potasio resultan más económicos se relacionan a continuación:

Nitrato cálcico amónico......128 ptas $/ \mathrm{kg}$. N.

Superfosfato ........... 83 ptas $/ \mathrm{kg} . \mathrm{P}_{2} \mathrm{O}_{5}$.

Sulfato potásico..........65 ptas $/ \mathrm{kg} . \mathrm{K}_{2} \mathrm{O}$.

Considerando estos precios, $100 \mathrm{~kg}$. de lodos expresados en materia seca, tendrían una valoración económica de:

Por su riqueza nitrogenada:

$3 \%$ en $\mathrm{N} \times 128 \mathrm{ptas} / \mathrm{kg} . \mathrm{N}=384$ ptas $/ 100 \mathrm{~kg}$.

Por su riqueza fosfórica:

$3,2 \%$ en $\mathrm{P}_{2} \mathrm{O}_{5} \times 83$ ptas $/ \mathrm{kg} \cdot \mathrm{P}_{2} \mathrm{O}_{3}=265$ ptas $/ 100 \mathrm{~kg}$.

Por su riqueza potásica:

$$
0,3 \% \text { en } \mathrm{K}_{2} \mathrm{O} \times 65 \mathrm{ptas} / \mathrm{kg} \cdot \mathrm{K}_{2} \mathrm{O}=19,5 \mathrm{ptas} / 100 \mathrm{~kg} \text {. }
$$

Por su riqueza mineral ........... $668,5 \mathrm{ptas} / 100 \mathrm{~kg}$.

La valoración económica por su riqueza orgánica es más difícil de realizar pues los precios del producto de referencia, el estiércol animal, dependen de la zona agrícola. En nuestra ciudad, carecemos prácticamente del mismo y sin embargo, en muchas granjas, el estiércol se entrega gratis mientras se proceda regularmente a su retiro.

Como poco, el gasto a realizar por el trasporte o el precio a pagar por su compra es de $1 \mathrm{pta} / \mathrm{kg}$. de estiércol fresco. Tomamos este valor como referen- 
cia. El poder horticola del mismo se mide por su contenido húmico que es señalado en la bibliografía como de un $5 \%$ sobre estiércol fresco.

El valor húmico de los lodos se establece por el grado de descomposición de la materia orgánica presente. Considerando que éste es del $34 \%$, la riqueza húmica aportada por $100 \mathrm{~kg}$. de lodos será de:

$$
50,4 \mathrm{~kg} . \times 0,34=17,238 \mathrm{kgs} \text {. }
$$

De estos valores se deduce que $100 \mathrm{Kg}$. de lodos sobre materia seca equivalen $\frac{17,238}{5} \times 100=344,7 \mathrm{Kg}$. de estiércol fresco y por tanto, la riqueza de la fracción orgánica de los lodos estudiados supone un valor de 3,45 ptas./Kg. sobre materia seca.

La riqueza fertilizante total de los lodos ascienden a:

$$
\begin{aligned}
& \text { Por su fracción mineral } \quad 6,68 \mathrm{ptas} / \mathrm{kg} \text {. } \\
& \text { Por su fracción orgánica } 3,44 \text { ptas } / \mathrm{kg} \text {. } \\
& \text { TOTAL } \overline{10,12 \text { ptas } / \mathrm{kg}} \text {. }
\end{aligned}
$$

\section{Conclusiones}

1.- Los lodos de las depuradoras urbanas ofrecen un poder fertilizante de interés agrícola ante el déficit de materia orgánica de los suelos y la insuficiente disponibilidad de estiércol tradicional.

2. El lodo de la Estación Depuradora de Aguas Residuales de Melilla se califica según la ley de Abonos (10 Junio 1976) como Abono Orgánico por su alto contenido en Materia Orgánica.

Su precio, dada su riqueza mineral y orgánica, puede ser estimado en 10 $\mathrm{ptas} / \mathrm{kg}$. de materia seca.

3. - Una huerta experimental con tres zonas dosificadas de la siguiente forma:

$$
\begin{aligned}
& \text { Zona "A".............Sin abono. } \\
& \text { Zona " } C \text { "'.............Con } 251 \text {. de abono. } \\
& \text { Zona " } D \text { "..............Con } 50 \text { l. de abono. }
\end{aligned}
$$

indica un mejor rendimiento de mejor dosificada. Dichos resultados pueden mejorarse a medida que el Nitrógeno del lodo vaya haciéndose con el tiempo un Nitrógeno inorgánico asimilable por las plantas.

4. - El lodo de la Estación Depuradora de Aguas Residuales de Melilla es especialmente acertado para la agricultura por su carencia de elementos tóxicos. El riesgo microbiológico también es eliminado por su exposición al Sol durante 24 horas. 